\title{
KEEFEKTIFAN MODEL CONNECTED DAN INTEGRATED DALAM PEMBELAJARAN IPS SMP DI KOTA YOGYAKARTA
}

\author{
Oleh : Idrus \\ LPMP Palu - Sulawesi Tengah
}

\begin{abstract}
This research aimed to: (1) analyze the differences in social studies learning achievement between the students using connected and integrated models and those using conventional model; and (2) analyze the hierarchy of the effect of the learning models among the connected, integrated, and conventional.

This experimental research employed a matching post-test comparison group design. The population of this research was National Standardized Schools of Junior Secondary Schools in Yogyakarta. The technique used for sample drawing was multistage sampling. In this research, the independent variable was the learning model which consisted of three categories: integrated, connected, and conventional models. The dependent variable was the mean score of students' learning achievement in social studies subject. Data collection was done by means of an achievement test. Instrument validation was done by discriminating power and difficulty index, while the reliability was calculated by KR-20. The pre-requisite test included normality and homogeneity tests. The normality test used Kolmogorov-Smirnov and the homogeneity test used Levene Test. Data were analyzed in one way anova analysis and continued with Scheffe comparison test on the significance level of 0.05 . The results of the experiment show that there are significant difference among the students' learning achievement who used integrated, connected, and conventional models. The continued test using Scheffe ensured that the integrated model was more effective than the connected and conventional models, while the connected model was more effective in improving the students' learning achievement in social studies subject compared with the conventional model. Therefore, the hierarchy of the effect of the learning models is first the integrated model followed by connected and conventional models.
\end{abstract}

Key words: Connected, Integrated Models, Social Studies Learning 


\section{A. PENDAHULUAN}

Ilmu Pengetahuan Sosial (IPS) atau disebut pula social studies merupakan salah satu mata pelajaran yang diberikan pada siswa di jenjang pendidikan dasar dan menengah. Barth (1990: 28) menyatakan "social studies is the interdiciplinary integration of social science and humanities concepts for the purpose of practicing citizenship skills of critical social issues." Clark (1978: 242) memberikan uraian, "someone has defined the social studies as a group of studies comprised of such subjects as history, geography, civies, anthropology, sociology, political science, problems of democracy, psychology, psychiatry, and sometimes philosophy and ethics, and call the social studies.

Tujuan mata pelajaran IPS adalah "untuk mengembangkan potensi peserta didik agar peka terhadap masalah sosial yang terjadi di masyarakat, memiliki sikap mental positif terhadap perbaikan segala ketimpangan yang terjadi dan terampil mengatasi setiap masalah yang terjadi sehari-hari baik yang menimpa dirinya maupun masyarakat." (Buchari Alma, 2010: 6) Sementara itu, menurut Etin Solihatin dan Raharjo (2008: 15) IPS bertujuan "untuk mendidik dan memberi bekal kemampuan dasar kepada siswa untuk mengembangkan diri sesuai dengan bakat, minat, kemampuan dan lingkungannya, serta berbagai bekal siswa untuk melanjutkan pendidikan ke jenjang yang lebih tinggi." Tasrif (2008: 3) menyatakan "IPS sangat penting untuk mendidik siswa mengembangkan pengetahuan, sikap, dan keterampilan agar dapat mengambil bagian secara aktif dalam kehidupannya kelak sebagai anggota masyarakat dan warga negara yang baik." Menjadi warga negara yang baik sebagai tujuan IPS juga ditekankan oleh Gross (Solihatin dan Raharjo, 2008: 15) bahwa "tujuan IPS adalah untuk mempersiapkan peserta didik menjadi warga negara yang baik dalam kehidupannya di masyarakat." Untuk mencapai tujuan IPS, maka pembelajaran harus dilaksanakan secara efektif. Pembelajaran yang efektif adalah "suatu pembelajaran yang memungkinkan siswa untuk belajar keterampilan, ilmu pengetahuan, dan sikap serta yang membuat siswa senang" (Sobri Sutikno, 2009: 173). Jadi, keefektifan pembelajaran pada dasarnya diukur dari pencapaian tujuan pembelajaran yang terdiri atas; aspek pengetahuan, sikap, dan keterampilan.

Mata pelajaran IPS terutama pada tingkat Sekolah Dasar (SD) dan Sekolah Menengah Pertama (SMP/MTs), seharusnya diajarkan secara terpadu karena menurut Sapriya (2009: 7) "ciri khas IPS sebagai mata pelajaran pada jenjang pendidikan dasar dan menengah adalah sifat terpadu (integrated) dari sejumlah mata pelajaran dengan tujuan agar mata pelajaran ini lebih bermakna bagi peserta didik." Abdullah Ide (2007: 146) menyatakan, "kurikulum terpadu (integrated curriculum) merupakan suatu produk dari usaha pengintegrasian 
bahan pelajaran dari berbagai macam pelajaran". Sugiyanto (2009: 126) meninjau dari perspektif siswa menyatakan "model pembelajaran terpadu pada hakikatnya merupakan suatu pendekatan pembelajaran yang memungkinkan siswa baik secara individu maupun kelompok aktif mencari, menggali, dan menemukan konsep serta prinsip secara holistik," Sementara itu, Zaim Elmubarok (2008: 81) menegaskan "pembelajaran terpadu menunjuk pada kegiatan belajar mengajar yang terorganisasikan secara lebih terstruktur yang bertolak pada tema-tema tertentu atau pelajaran sebagai titik pusatnya (center core/center of interest).Terkait dengan pembelajaran terpadu, Oemar Hamalik (2007: 33) menyatakan "kurikulum sekolah sebaiknya tidak disusun berdasarkan mata pelajaran terpisah, melainkan merupakan perpaduan sejumlah mata pelajaran yang memiliki ciri-ciri yang sama, yang menjadi suatu bidang studi (broudfield)," akan tetapi, menerapkan pembelajaran terpadu tentu tidak mudah karena berbagai faktor perlu dipersiapkan terutama kesiapan guru. Schug and Cross (1998: 5), menegaskan "meaningful curriculum integration requires a large investment in staff development and planning. Curriculum integration requires teachers who are or can become sufficiently expert in understanding their subjects to be able to make meaningful connections across the disciplines."

Menurut Fogarty (1991) ada 10 model yang dapat diterapkan untuk melaksanakan pembelajaran terpadu atau mengintegrasikan kurikulum (integrated curricluum, yaitu; "fragmanted, connected, nested, sequenced, shared, webbed, threaded, integrated, immersed, dan networked." Sementara itu, Pusat Kurikulum (2006.a:8) menawarkan tiga model yang dapat dijadikan rujukan untuk mengimplementasikan pembelajaran terpadu, yakni; "connected, webbed, dan integrated."

Fakta yang ada sampai saat ini pembelajaran IPS di SMP masih dilakukan secara terpisah. Padahal sejak tahun 2006 atau sejak Kurikulum Tingkat Satuan Pendidikan (KTSP) dikeluarkan, seharusnya IPS diberikan pada siswa secara terpadu karena merupakan amanat Peraturan Menteri Pendidikan Nasional (Permendiknas) 22 Tahun 2006 tentang Standar Isi yang menegaskan bahwa "substansi mata pelajaran IPA dan IPS pada SMP/MTs merupakan "IPA Terpadu" dan "IPS Terpadu." Harapan agar guru melaksanakan pembelajaran IPS terpadu dengan memilih salah satu atau beberapa model pengintegrasian kurikulum di atas, tampaknya masih jauh dari kenyataan. Praktis belum banyak sekolah yang bersungguh-sungguh untuk menerapkan pembelajaran IPS Terpadu. Oleh karena itu, sinyalemen Buchari Alma, dkk. (2010: 5) sangat tepat ketika menyatakan "pembelajaran IPS sebagian besar masih dilaksanakan secara terpisah. Hal ini disebabkan karena guru memang belum mengerti dan belum memahami, apa IPS Terpadu."

Sulit bahkan tidak mungkin bagi guru IPS dapat melaksanakan suatu 
model pembelajaran jika tidak mengetahui apa dan bagaimana prosedur operasional model tersebut. Secara objektif diakui, fenomena pembelajaran IPS Terpadu yang belum dilaksanakan oleh guru IPS juga terjadi di Yogyakarta. Hasil preliminary study atau pra survai dan diskusi dengan beberapa guru IPS menunjukkan bahwa realitas empiris jauh dari harapan ideal dengan indikator sebagian SMP masih menggunakan penjadwalan parsial yang berarti belum menerapkan pembelajaran terdapu dan bagi guru IPS yang sudah mulai melaksanakan pembelajaran terpadu juga belum konsisten dalam secara kontinyu.

Kendala dalam melaksanakan pembelajaran IPS terpadu di Kota Yogyakarta adalah; (1) kurangnya guru IPS yang berlatar belakang disiplin IPS; (2) guru IPS belum mengetahui model-model pembelajaran terpadu dan penerapannya; (3) kemampuan guru IPS sangat terbatas dalam membuat rekonstruksi/pemetaan $\mathrm{SK} / \mathrm{KD}$ atau jaringan tema dan mengintegrasikan materi serumpun dalam rangka pengembangan silabus dan penyusunan Rencana Pelaksanaan Pembelajaran (RPP); (4) guru IPS memiliki keterbatasan dalam melakukan pengembangan materi terpadu sesuai hasil pemetaan, silabus, dan RRP yang telah disusun berdasarkan model pembelajaran terpadu yang telah dipilih; (5) pemahaman guru yang menilai bahwa pembelajaran parsial lebih tepat dibanding pembelajaran terpadu di SMP.

Berdasarkan latar belakang, pembatasan, dan fokus masalah, maka dapat dirumuskan permasalahan sebagai berikut: (1) Apakah terdapat perbedaan hasil belajar IPS, antara siswa yang belajar dengan model connected, integrated, dan konvensional ? dan (2) Model manakah yang paling efektif di antara model connected, integrated, dan konvensional? Jawaban atas permasalahan tersebut, secara tentatif dalam bentuk hipotesis dirumuskan sebagai berikut; (1) Ada perbedaan hasil belajar siswa pada mata pelajaran IPS, antara yang diajar dengan model connected, integrated, dan konvensional dan (2) Urutan keefektifan model pembelajaran dalam mencapai tujuan pembelajaran IPS (meningkatkan hasil belajar siswa) adalah: Model integrated, model connected, dan model konvensional.

\section{B. METODE PENELITIAN}

Penelitian eksperimen ini menggunakan desain Randomized PosttestOnly Control/Comparasion Group Design. Penelitian dilaksanakan pada tiga SMP SSN di Kota Yogyakarta, yaitu; (1) SMP Negeri 3; (2) SMP Negeri 6; dan (3) SMP Negeri 12. Waktu pelaksanaan penelitian pada semester genap tahun pelajaran 2009/2010, pada Januari-Pebruari 2010 (enam kali pertemuan/ pembelajaran). Populasi penelitian adalah semua SMP katagori Sekolah Standar Nasional (SSN) di Kota Yogyakarta yang berjumlah 13 SMP SSN. 
Sampel dipilih menggunakan teknik desain random multistage, dengan tahap sebagai berikut:

Pada tahap pertama, dipilih tiga dari 13 SMP SSN dengan menggunakan random sampling dan terpilih tiga SMP SSN, yakni; SMP Negeri 3 Yogyakarta, SMP Negeri 6 Yogyakarta, dan SMP Negeri 12 Yogyakarta. Pada tahap kedua, dipilih tiga kelas dari tiga SMP SSN yang telah disampel dengan menggunakan random sampling dan terpilih tiga kelas, yakni; kelas VIII A SMP Negeri 3 Yogyakarta, kelas VIII D SMP Negeri 6 Yogyakarta, dan kelas VIII D SMP Negeri 3 Yogyakarta, dan pada tahap ketiga menentukan model pembelajaran yang akan diterapkan pada kelas yang telah disampel dengan menggunakan random sampling dan hasilnya; untuk kelas VIII D SMP Negeri 3 menggunakan model integrated, kelas VIII A SMP Negeri 6 menggunakan model connected, kelas VIII A SMP Negeri 12 menggunakan model konvensional

Variabel penelitian terdiri atas variabel bebas (independen) dan variabel terikat (dependen). Variabel $\mathrm{X}$ adalah model pembelajaran dengan tiga katagori, yakni; Pembelajaran terpadu model connected, pembelajaran terpadu model integrated, dan model pembelajaran konvensional. Variabel Y adalah hasil belajar yang berupa skor rata-rata mata pelajaran IPS.

Instrumen pengumpulan data menggunakan tes karena yang diukur adalah hasil belajar siswa. Bentuk tes yang digunakan adalah tes objektif untuk mengukur kompetensi kognitif siswa. Validasi instrumen meliputi dua aspek, yaitu; (1) validasi ahli (experts judgment) dan (2) validasi empiris. Untuk validasi ahli meliputi; validasi konstruk dan isi tes, sedangkan validasi empiris dilakukan uji coba di kelas IX F SMP Negeri 1 Yogyakarta. Daya beda dihitung dengan menggunakan rumus. $\mathrm{D}=\frac{\sum A-\sum B}{n}$, dengan kriteria pengambilan keputusan sebagai berikut: 0,40 atau lebih : Sangat baik, 0,300,39 : Cukup baik, 0,20-0,29: Minimum, perlu diperbaiki, dan 0,19 ke bawah : Jelek, dibuang atau dirombak.

Berdasarkan daya pembeda serta kriteria pengambilan keputusan, maka dari 30 butir soal ternyata ada lima soal yakni item 1, 2, 5, 16, dan 18 yang tidak valid. Kelima butir soal tersebut memperoleh daya pembeda 0,10 sehingga dinyatakan tidak valid karena berada di bawah 0,19 . Selanjutnya

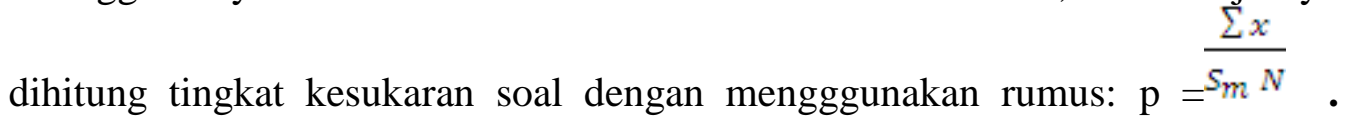
Kriteria pengambilan keputusan sebagai berikut: $0,00-0,30$ : sukar, 0, 31 0,70 : sedang, dan $0,70-1,00:$ mudah.

Hasil perhitungan tingkat kesukaran soal menunjukkan bahwa dari 30 butir soal ternyata item 5 memiliki tingkat kesukaran 0,76 dan item 8 memiliki tingkat kesukaran 0,73. Oleh karena itu, kedua soal ini ditolak karena 
dikategorikan mudah. Dengan demikian secara keseluruhan setelah melakukan perhitungan daya pembeda soal dan analisis tingkat kesukaran soal, dapat disimpulkan soal yang dinyatakan tidak valid adalah soal nomor 1,2,5,16, dan 18 sedangkan soal yang dinyatakan mudah adalah soal nomor 5 , dan 8 .

Secara keseluruhan dari 30 soal yang telah dianalisis tercatat $80 \%$ layak digunakan sebagai instrumen pengumpulan data sedangkan $20 \%$ tidak layak digunakan (dibuang). Dari butir-butir instrumen yang valid (24 butir) dilakukan perhitungan reliability dengan rumus KR 20 karena lebih tepat untuk tes yang jawabannya dikotomis yakni benar-salah atau hanya satu jawaban benar. Instrumen dinyatakan reliabel apabila angka yang diperoleh dalam perhitungan KR-20 sama atau lebih besar dari 0,70. Berdasarkan hasil perhitungan KR-20 diperoleh nilai 0,838 sehingga dapat dinyatakan instrumen tes yang digunakan dalam penelitian ini memiliki nilai reliabilitas tinggi.

Teknik analisis data menggunakan anova satu jalur dan uji lanjut menggunakan Scheffe. Sebelum melakukan uji hipotesis, terlebih dahulu dilakukan uji persyaratan yaitu; uji normalitas dengan Kolmogorov-Smirnov dan homogenitas varians dengan Levene Test. Keseluruhan hipotesis yang diuji dalam penelitian ini adalah (1) Ho : M1 = M2 = M3 dan (2) a. Ho: $\mathrm{M} 1=\mathrm{M} 2$, b. Ho: $\mathrm{M} 2=\mathrm{M} 3$, c. Ho: $\mathrm{M} 1=\mathrm{M} 3$

\section{HASIL DAN PEMBAHASAN}

\section{Deskripsi, Analisis Data, dan Pengujian Hipotesis}

Ada tiga kelompok data dalam penelitian ini, yakni; data hasil belajar model integrated, connected, dan konvensional. Data hasil belajar model integrated memperoleh skor tertinggi 22, skor terendah 11 , mean 18,238, median 19,000, modus 21,000, standar deviasi sebesar 3.223, dan varians sebesar 10,390. Data hasil belajar siswa yang menggunakan model connected memperoleh skor tertinggi 20, skor terendah 12 , mean 14,857 , median 15,000 , modus 12,000, standar deviasi 2,516, dan varians 6,329. Sementara itu, data hasil belajar siswa yang menggunakan model konvensional memperoleh skor tertinggi 16, skor terendah 7, mean sebesar 11, 095, median 11,000, modus 7,00, standar deviasi 2,982, dan varians 8,890 .

Sebelum melakukan analisis anova satu jalur, terlebih dahulu dilakukan pemeriksaan data dengan melakukan uji normalitas dan homogenitas data. Uji normalitas dilakukan untuk memastikan apakah data berdistribusi normal.? Uji normalitas menggunakan kaedah pengujian, jika $\mathrm{p} \geq_{0,05}$, maka Ho diterima berarti tidak ada perbedaan antara distribusi data hasil penelitian dengan distribusi normal baku sehingga dapat disimpulkan bahwa data hasil penelitian berdistribusi normal (memenuhi persyaratan uji parametrik). Dengan menggunakan SPSS versi 18.00, hasilnya dapat dilihat sebagai berikut. 
Tabel 1

Rangkuman hasil uji Normalitas Data

\begin{tabular}{|c|l|c|c|c|c|}
\hline No & Kelompom Data & $\mathbf{N}$ & $\begin{array}{c}\text { Kolmogorov } \\
\text {-Smirnov Z }\end{array}$ & $\mathbf{p}$ & Kesimpulan \\
\hline $\mathbf{1}$ & \multicolumn{1}{|c}{} & $\mathbf{3}$ & $\mathbf{4}$ & $\mathbf{5}$ & $\mathbf{6}$ \\
\hline 1 & Model Integrated & 21 & 0,843 & 0,477 & Normal \\
\hline 2 & Model Connected & 21 & 0,691 & 0,726 & Normal \\
\hline 3 & Model Konvensional & 21 & 0,548 & 0,925 & Normal \\
\hline
\end{tabular}

Hasil uji normalitas dan dikonfirmasi pada kaedah pengujian yang telah ditetapkan di atas, dapat disimpulkan bahwa ketiga kelompok data, yakni; data model integrated, model connected, dan konvensional berdistribusi normal karena ketiga kelompok data memilik $p>0,05$. Selanjutnya dilakukan uji homogenitas dengan tujuan mengetahui apakah data berasal dari kelompok populasi yang homogen atau sejenis.? kaedah pengujian adalah, jika $\mathrm{p} \geq_{0,05 \text {, }}$ maka Ho diterima berarti tidak ada perbedaan varians hasil belajar dari kelompok integrated, connected, dan konvensional. Artinya varians ketiga kelompok berasal dari populasi yang homogen. Dengan menggunakan bantuan SPSS versi 18.00, hasilnya dapat dilihat sebagai berikut.

Tabel 2

Rangkuman hasil uji Homogenitas Data

\begin{tabular}{|c|c|c|c|c|}
\hline Levene Statistik & df1 & df2 & $\mathrm{p}$ & Kesimpulan \\
\hline 0,890 & 2 & 60 & 0,416 & Homogen \\
\hline
\end{tabular}

Berdasarkan hasil uji homogenitas dan dikonfirmasi pada kaedah pengujian yang telah ditetapkan, dapat disimpulkan Ho diterima artinya varians ketiga kelompok berasal dari populasi yang homogen. Dengan demikian persyaratan uji parametrik telah dipenuhi sehingga analisis untuk menguji hipotesis penelitian dapat menggunakan one way anova. Kaedah pengambilan keputusan, jika $\mathrm{p}<0,05$, maka Ho ditolak, artinya ada perbedaan yang signifikan antara hasil belajar siswa yang belajar dengan model integrated, connected, dan konvensional. Hipotesis pertama menguji Ho: $\mathrm{M} 1=\mathrm{M} 2=\mathrm{M} 3$ dengan tujuan pengujian mengetahui perbedaan mean siswa yang belajar dengan menggunakan model integrated, model connected, dan model konvensional. Berdasarkan hasil pengolahan SPSS versi 18.00, dapat dilihat sebagai berikut.

Tabel 3

Rangkuman hasil uji anova satu jalur (one way anova) 


\begin{tabular}{|c|c|c|c|c|c|}
\hline $\begin{array}{c}\text { Sumber } \\
\text { Varians }\end{array}$ & $\begin{array}{c}\text { Jumlah } \\
\text { Kuadrat } \\
(\mathrm{JK})\end{array}$ & $\begin{array}{c}\text { Derajat } \\
\text { Kebebasan } \\
(\mathrm{dk})\end{array}$ & $\begin{array}{c}\text { Rata-rata } \\
\text { Kuadrat } \\
(\mathrm{MK})\end{array}$ & $\mathrm{F}_{\mathrm{o}}$ & $\mathrm{p}$ \\
\hline 1 & 2 & 3 & 4 & 5 & 6 \\
\hline Antar Grup & 536,222 & 2 & 268,111 & 31,408 & 0,000 \\
\hline Dalam Grup & 512,190 & 60 & 8,537 & & \\
\hline Total & 1048,413 & 62 & & & \\
\hline
\end{tabular}

Hasil perhitungan diperoleh nilai $\mathrm{F}_{0}$ sebesar 31,408 dan $\mathrm{p}=0,000$. Karena nilai p 0,000 <0,05, berarti Ho ditolak. Dengan demikian ketiga model memiliki perbedaan yang signifikan $(\mathrm{M} 1 \neq \mathrm{M} 2 \neq \mathrm{M} 3)$. Selanjutnya dilakukan uji hipotesis kedua, yakni Ho: M1 = M2, Ho: M2 = M3, dan Ho: M1 = M3. Berdasarkan hasil uji hipotesis 1 yang menyimpulkan ada perbedaan yang signifikan antara model integrated, connected, dan konvensional, berarti perlu dilakukan post hoc untuk menganalisis hirarkis keefektifan antara model integrated, connected, dan konvensional. Dari ketiga model tersebut, manakah yang paling efektif meningkatkan hasil belajar siswa pada mata pelajaran IPS.? Oleh karena itu, dilakukan uji lanjut menggunakan analisis scheffe untuk membandingkan antara model integrated dengan model connected, model integrated dengan konvensional, dan antara model connected dengan model konvensional. Berdasarkan data hasil penelitian yang diolah dengan menggunakan SPSS versi 18,00, hasilnya dapat dilihat pada tabel berikut.

Tabel 4

Rangkuman hasil uji scheffe

\begin{tabular}{|c|c|c|c|c|}
\hline \multicolumn{2}{|c|}{$\begin{array}{c}\text { Model yang } \\
\text { diperbandingkan }\end{array}$} & \multirow{2}{*}{$\begin{array}{c}\text { Harga } \\
\text { perbedaan } \\
\text { rata-rata }\end{array}$} & $\mathrm{p}$ & Kesimpulan \\
\cline { 1 - 4 } Model 1 & Model 2 & 3 & 4 & 5 \\
\hline 1 & 2 & 3,381 & 0,002 & Signifikan \\
\hline Integrated & Connected & 7,143 & 0,000 & Signifikan \\
\hline Integrated & Konvensional & 3,762 & 0,000 & Signifikan \\
\hline Connected & Konvensional & 3 &
\end{tabular}

Hasil analisis scheffe menunjukkan Ho ditolak, karena semua model yang dibandingkan memperoleh $\mathrm{P}<0,05$, artinya ada perbedaan yang signifikan di antara ketiga model tersebut. Perbandingan keefektifan antara model integrated dan connected memperoleh perbedaan mean difference 3,381 dengan $\mathrm{p}=0,002$. Karena $\mathrm{p}$ sebesar 0,002 $<0,05$, dapat disimpulkan terdapat perbedaan yang signifikan antara model integrated dengan model connected. 
Perbandingan keefektifan antara model integrated dan model konvensional memperoleh mean difference 7,143 dengan $\mathrm{p}=0,000$. Karena $\mathrm{p}$ sebesar 0,000 $<0,05$, maka dapat dinyatakan terdapat perbedaan yang signifikan antara model integrated dengan model konvensional. Perbandingan keefektifan antara model connected dengan model konvensional, diperoleh mean difference 3,762 dengan $\mathrm{p}=0,000$. Karena $\mathrm{p}$ sebesar $0,000<0,05$, maka dapat dinyatakan terdapat perbedaan hasil belajar yang signifikan antara model connected dengan model konvensional.

\section{Pembahasan}

Hasil pengujian hipotesis pertama tentang perbedaan hasil belajar siswa pada mata pelajaran IPS yang menggunakan model integrated, connected, dan konvensional menunjukkan penolakan terhadap Ho karena nilai p 0,000 $<0,05$. Penolakan terhadap Ho berarti penerimaan terhadap $\mathrm{H}_{\mathbf{1}}$. Oleh karena itu, dapat dinyatakan ada perbedaan yang signifikan hasil belajar siswa pada mata pelajaran IPS, antara yang belajar dengan model connected, integrated, dan konvensional.

Temuan eksperimen memperkuat pandangan teoretis yang menyatakan penerapan pembelajaran terpadu lebih baik dan lebih efektif dibandingkan pembelajaran terpisah atau pembelajaran parsial (fragmentasi). Temuan eksperimen juga menggugurkan keyakinan kebanyakan guru IPS yang menilai pembelajaran konvensional seperti yang dilakukan selama ini lebih tepat untuk meningkatkan hasil belajar siswa SMP. Selain itu, anjuran yuridis (Permendiknas Nomor 22 Tahun 2006 tentang Standar Isi) untuk melaksanakan pembelajaran terpadu mendapat penguatan ilmiah karena terbukti pembelajaran terpadu yang direpresentasikan melalui penerapan model integrated dan connected lebih efektif meningkatkan hasil belajar siswa dibanding pembelajaran parsial yang direpresentasikan melalui penerapan pembelajaran konvensional.

Keberhasilan model integrated dan connected dalam meningkatkan hasil belajar siswa pada mata pelajaran IPS tidak terlepas dari keunggulan pembelajaran terpadu. Di antara berbagai keunggulan pembelajaran terpadu adalah lebih bermakna dibandingkan pembelajaran terfragmentasi. Kebermaknaan ini merupakan salah satu ciri dan karakteristik pembelajaran terpadu baik model integrated maupun model connected. Hal ini sesuai dengan keyakinan Depdiknas bahwa "pembelajaran terpadu memungkinkan kegiatan belajar bermakna bagi anak, sehingga hasilnya dapat bertahan lama" (Trianto, 2007: 12). Oemar Hamalik. (2007: 36) menjelaskan "pendekatan integratif, yang juga dikenal dengan nama pendekatan terpadu, bertitik tolak dari suatu keseluruhan atau kesatuan yang bermakna dan terstruktur." Demikian pula 
Nana Syaodih Sukmadinata (2008: 135-140), menyatakan "belajar bermakna lebih lama dikuasai daripada belajar menghafal. Dengan demikian belajar bermakna lebih efisien dibandingkan dengan belajar menghafal."

Pembelajaran yang bermakna memungkinkan siswa memperoleh pengetahuan dan pengalaman langsung yang lebih mendalam karena siswa dapat mengintegrasikan atau menghubungkan berbagai pengetahuan dan pengalamannya dalam proses pembelajaran. Bahkan melalui pembelajaran terpadu kebermaknaan juga ditunjukkan dengan memberikan peluang yang besar pada siswa untuk mengaitkan antara materi yang sedang dipelajari dengan lingkungan sekitar di mana siswa berada. Hal inilah yang ditekankan dalam materi pembelajaran terpadu (bahan ajar) model integrated dan connected yang kemudian dijabarkan dalam proses pembelajaran oleh guru IPS pada saat eksperimen, sehingga "melalui pembelajaran terpadu, peserta didik dapat memperoleh pengalaman langsung, dapat menambah kekuatan untuk menerima, menyimpan, dan memproduksi kesan-kesan tentang hal-hal yang dipelajarinya." Buchari Alma, dkk. (2009: 5).

Berdasarkan eksperimen yang telah dilakukan, kebermaknaan dalam pembelajaran terpadu terwujud karena berbagai fenomena atau tema yang dibahas tidak hanya ditinjau dari satu sudut pandang melainkan dari berbagai perspektif. Misalnya; ketika membahas tentang tema "Merajut hubungan sosial," tidak hanya dikaji dari aspek sosiologis semata sebagaimana ditekankan dalam pembelajaran parsial sehingga pemahaman siswa sangat terbatas, melainkan dikaji pula dari aspek sejarah, ekonomi, dan geografi.

Situasi pembelajaran semacam ini mendorong siswa untuk memaknai permasalahan lebih mendalam bahkan kemudian menyadari bahwa dalam kehidupan sekitar juga selalu terkait antara satu dengan yang lain. Dengan demikian melalui pembelajaran terpadu terjadi transformasi kesadaran pada diri siswa dari sekadar memahami kemudian menjadi lebih fungsional. Siswa dapat menarik makna pembelajaran ke dalam kehidupan sehari-hari sehingga pembelajaran tersebut lebih efektif.

Selain lebih bermakna, karakteristik pembelajaran terpadu (integrated dan connected) adalah bersifat holisitik, otentik, dan mengarahkan siswa aktif. Karakteristik ini sangat nyata dalam eksperimen terbukti dari adanya mean difference yang signifikan setiap kelompok eksperimen dan kelas kontrol. Bersifat holistik berarti pemahaman siswa yang diperoleh melalui pembelajaran terpadu lebih menyeluruh mencakup berbagai aspek pengetahuan. Paling tidak, sebuah tema dipahami dari empat perspektif, yakni; geografi, sejarah, ekonomi, dan sosiologi.

Ciri lain bersifat otentik sehingga siswa langsung menyadari hakikat yang sedang dipelajari terutama yang berkaitan dengan fenomena sosial. Misalnya, keberadaan manusia tidak dapat hidup tanpa keterlibatan orang lain. 
Dalam eksperimen yang menggunakan bahan ajar model integrated dan connected secara gamblang sifat otentik terlihat pada bahan ajar maupun pada saat proses pembelajaran. Hal ini memungkinkan siswa belajar sesuai dengan minatnya karena setiap yang dipelajari selalu dihubungkan dengan kenyataan otentik.

Temuan ini sejalan dengan teori perkembangan kognitif. Piaget mengemukakan bahwa seorang anak mengikuti empat tahapan perkembangan kognitif, yakni: sensorimotor, praoperasional, operasional konkrit, dan operasi formal. Siswa SMP sudah menuju taraf berpikir operasional formal, meskipun ciri operasional konkrit juga masih tampak. Salah satu ciri pembelajaran terpadu adalah otentik yang antara lain dapat dimaknai sebagai penyajian pembelajaran yang lebih konkrit tanpa mengabaikan aspek kritis menuju operasional formal.

Adanya unsur kebermaknaan, holistik, otentik, dan keaktifan dalam pembelajaran IPS terpadu menimbulkan efek retensi yang lebih kuat dibandingkan pembelajaran parsial. Seperti diketahui salah satu faktor yang mempengaruhi hasil belajar atau kemampuan kognitif siswa adalah kuat dan lemahnya retensi yang dimiliki siswa. Jika retensi kuat, maka pengetahuan bertahan lama sehingga dapat dieksplorasi kembali pada saat dibutuhkan. Oleh karena itu, hasil penelitian tampaknya sejalan dengan kesimpulan Sausa (Masnur Muslich, 2007: 58) yang menilai "pembelajaran terpadu dapat meningkatkan hasil belajar siswa," sehingga Muhammad Nu'man Sumantri (2001: 252) memastikan "IPS Terpadu akan lebih baik dibandingkan dengan IPS yang terpisah-pisah."

Retensi yang kuat berdampak pada hasil belajar yang optimal karena pada saat mengikuti tes, siswa dapat mengungkap kembali apa yang telah dipelajari beberapa waktu yang lalu. Retensi yang kuat inilah yang berhasil diwujudkan dalam pembelajaran IPS Terpadu model integrated dan connected. Sebaliknya jika retensi lemah, maka pengetahuan yang telah dipelajari akan mengendap dan sulit dieskplorasi pada saat dibutuhkan sehingga hasil belajar sulit dioptimalkan. Hal ini terjadi dalam pembelajaran parsial atau pembelajaran terpisah dengan model konvensional.

Hipotesis kedua menyatakan bahwa $\mathrm{H} 1: \mathrm{M} 1 \neq \mathrm{M} 2 \neq \mathrm{M} 3$ dan Ho: $\mathrm{M} 1=$ M2 = M3. Jadi, $\mathrm{H}_{1}$ menegaskan model integrated lebih efektif dibanding model connected, model connected lebih efektif dibanding model konvensional, dan model integrated lebih efektif dibanding model konvensional. Hasil eksperimen kemudian menguji Ho yang ternyata ditolak. Oleh karena itu, temuan eksperimen dapat dibahas lebih lanjut bahwa model integrated lebih efektif dibanding model connected, model connected lebih efektif dibanding model konvensional, dan model integrated tentu lebih efektif dibanding model konvensional. 
Perbandingan antara model integrated dan connected berada pada mean difference 3,381 atau jika dibandingkan antara model connected dan integrated, maka memiliki mean difference -3,381 dengan propabilitas 0,002. Karena p 0,002 < 0,05, maka kaedah pengujian yang berlaku adalah model integrated dan connected memiliki perbedaan signifikan di mana mean model integrated lebih tinggi dibanding mean model connected $(18,24>14,86)$. Dengan demikian, model integrated lebih efektif meningkatkan hasil belajar siswa dibanding model connected.

Model integrated dan connected merupakan pendekatan pembelajaran terpadu, tetapi dalam memadukan berbagai mata pelajaran, model integrated lebih mendalam dibanding model connected. Keunggulan utama model integrated adalah setiap mata pelajaran disatukan dengan prinsip integrasi sedangkan model connected menggunakan prinsip menghubungkan atau mengaitkan. Proses pengintegrasian mata pelajaran baik dalam persiapan maupun pelaksanaan di kelas jauh lebih sulit dibanding proses mengaitkan. Meskipun lebih sulit, model integrated mampu menuntun siswa berpikir lebih kritis dan sistematis karena model integrated didesain dengan cara yang lebih fokus. Pola pemikiran kritis sistematis membuat pembelajaran model integrated yang diterapkan di kelas VIII SMP Negeri 3 Yogyakarta mampu memberikan hasil belajar yang lebih efektif dibanding model connected.

Keunggulan model integrated juga terlihat ketika dibandingkan dengan model konvensional. Bahkan perbandingan antara model integrated dan model konvensional memiliki mean difference yang lebih tinggi yakni 7,143 dengan probalitas 0,000 . Karena p 0,000 $<0,05$, maka model integrated dan model konvensional memiliki perbedaan mean yang signifikan. Dengan demikian, model integrated lebih efektif dibandingkan model konvensional.

Bagaimana dengan perbandingan antara model connected dan konvensional? Sesuai dengan hasil analisis scheffe ditemukan perbandingan antara model connected dan konvensional memiliki mean difference 3,762 dan probalitas 0,000. Karena p 0,000 $<0,05$, maka Ho ditolak, artinya ada perbedaan yang signifikan antara hasil belajar model connected dibanding model konvensional. Model connected memiliki mean sebesar 14,86 sedangkan model konvensional memiliki mean sebesar 11,09. Jadi mean model connected lebih tinggi dibanding mean konvensional. Karena M2 > M3, maka dapat disimpulkan model connected lebih efektif meningkatkan hasil belajar siswa dibanding model konvensional. Dengan demikian secara keseluruhan telah ditemukan urutan model pembelajaran yang paling efektif yakni; model integrated, connected, dan konvensional.

\section{E. Simpulan}

Berdasarkan hasil pengujian hipotesis dan pembahasan, dapat disimpulkan sebagai berikut: (1) Ada perbedaan hasil belajar IPS yang 
signifikan, antara siswa yang belajar dengan model connected, integrated, dan konvensional, dan (2) Model integrated lebih efektif dari pada model connected dengan mean difference 3,382. Model integrated lebih efektif dari model konvensional dengan mean difference 7,143, model connected lebih efektif dari model konvensional dengan mean difference 3,762, sehingga dapat disimpulkan urutan model yang paling efektif adalah model integrated, kemudian model connected, dan yangf terakhir model konvensional.

\section{Daftar Pustaka}

Abdullah Ide. (2007). Pengembangan kurikulum teori \& praktik. Yogyakarta: AR-Ruzz Media

Barth, J.L. (1990). Methods of instruction in social studies education. Third Edition. Boston: University Press of America. Inc.

Buchari Alma, dkk. (2010). Pembelajaran studi sosial. Bandung: Alfabeta.

Clark, L.H, Raymond L. Klein \& John B. Burks. (1978). The american secondary school curriculum. Second Edition. New York: Macmillan Publishing. Co. Inc.

Depdiknas. (2007). Buku saku kurikulum tingkat satuan pendidikan (ktsp) sekolah menengah pertama. Jakarta: Depdiknas . (2006). Lampiran peraturan meneteri pendidikan nasional nomor 22 tahun 2006 tanggal 23 mei 2006. standar isi. Jakarta: Depdiknas

Etin Solihatin \& Raharjo. (2008). Cooperative learning, analisis model pembelajaran IPS. Jakarta: Bumi Aksara.

Fogarty, R. (1991). The mindfull schools: How to integrate the curricula. Palatine, Illionis: IRI/Skylight Publising. Inc.

Masnur Muslich. (2007). KTSP dasar pemahaman dan pengembangan. Jakarta: Bumi Aksara.

Moh. Sobri Sutikno. (2009). Belajar dan pembelajaran, "upaya kreatif dalam mewujudkan pembelajaran yang berhasil. Bandung: Prospect

Muhammad Nu'man Sumantri. (2001). Menggagas Pembelajaran Pendidikan IPS. Bandung: Remaja Rosdakarya.

Nana Syaodih Sukmadinata. (2008). Pengembangan kurikulum teori dan praktek. Bandung: Remaja Rosdakarya.

Oemar Hamalik. (2007). Dasar-dasar pengembangan kurikulum. Bandung: Remaja Rosdakarya.

Pusat Kurikulum. (2006). Panduan pengembangan IPS terpadu. Sekolah menengah pertama/madrasah tsnawiyah (SMP/MTs). Jakarta: Balitbang Depdiknas.

Sapriya. (2009). Pendidikan IPS konsep dan pembelajaran. Bandung: Remaja Rosdakarya.

Schug, M.C \& Baverly Cross. (Maret 1998). The dark side of curriculum integration in social studies. The Social Studies. Vol. 89. Diambil pada tanggal 20 Agustus 2009 dari http://proquest.umu.com/pqdweb 
Sugiyanto. (2009). Model-model pembelajaran inovatif. Surakarta: Panitia Sertifikasi Guru (PSG) Rayon 13 FKIP UNS Surakarta.

Trianto. (2007). Model pembelajaran terpadu dalam teori dan praktek. Jakarta: Pustaka

Zaim Elmubarok. (2008). Membumikan pendidikan nilai: mengumpulkan yang terserak, menyambung yang terputus, dan menyatukan yang tercerai. Bandung: Alfabeta

Biodata Penulis: Idrus, S.Pd, SH. M.Pd adalah widyaiswara pada Lembaga Penjaminan Mutu Pendidikan (LPMP) Sulawesi Tengah di Palu. Sebelum menjadi widyaiswara (2007), selama 3 tahun sebagai guru IPS Sejarah di SMPN 1 Marawola, 8 tahun sebagai guru Sejarah dan Tata Negara di SMAN 1 Marawola, SMAN 2 Dolo, dan SMAN Madani Palu. Gelar Sarjana Pendidikan Sejarah diperoleh pada tahun 1994 dari Universitas Tadulako Palu dengan predikat cumlaude, gelar Sarjana Hukum diperoleh pada tahun 2007 dari Universitas Muhammadiyah Palu dengan predikat cumlaude, dan pada tahun 2008 tercatat sebagai mahasiswa prodi Pendidikan IPS Pascasarjana Universitas Negeri Yogyakarta yang berhasil diselesaikan pada tanggal 30 Juni 2010 dengan predikat cumlaude. 